\title{
Unusual clinical features associated with congenital generalized lipodystrophy type 4 in a patient with a novel E211X CAVIN1 gene variant
}

Ekaterina Sorkina* (D), Polina Makarova, Liubov Bolotskaya, Irina Ulyanova, Tatyana Chernova and Anatoly Tiulpakov

\begin{abstract}
Background: Congenital generalized lipodystrophy (CGL) is a rare disorder characterized by the lack of adipose tissue and metabolic complications with predominantly autosomal recessive inheritance. There are 6 different genes known to cause CGL with 4 main types recognized to date, which differ by the degree of fat loss, association with mental retardation and metabolic disorders, with CGL type 1 and 2 being the most common. Twenty seven cases of CGL type 4 from Japan, Oman, UK, Turkey, Mexico, Saudi Arabia, USA were reported previously. This report details our clinical experience with the first patient from Russia with CGL type 4.
\end{abstract}

Case presentation: A 36-year-old patient, who has been suffering from generalized lipoatrophy since the first months of life and myopathy and gastrointestinal dysmotility since early childhood, developed dysmenorrhea and diabetes mellitus at the age of 19, bilateral cataracts when she was only 22 y.o., osteoporosis with vitamin D deficiency and hypocalcemia at the age of 28, diabetic foot syndrome and hyperuricemia when she was 35 y.o. Sequencing of lipodystrophy candidate genes detected a novel pathogenic homozygous variant p.631G $<\mathrm{T}$ : p.E211X in the CAVIN1 gene, confirming the diagnosis of CGL type 4.

Conclusions: In comparison with previously reported patients with CGL type 4, our patient has diabetes mellitus, vitamin D deficiency, hypocalcemia, bilateral cataracts and hyperuricemia. All these manifestations are known to be associated with other lipodystrophy syndromes, but to our knowledge it is the first time they have been reported to be associated with CGL type 4.

Keywords: Congenital generalized lipodystrophy type 4, CAVIN1, Insulin dependent diabetes mellitus, Vitamin D deficiency, Bilateral cataracts

\section{Background}

Congenital generalized lipodystrophy (CGL) is a rare disorder characterized by the lack of adipose tissue and metabolic complications with predominantly autosomal recessive inheritance. There are 6 different genes known to cause CGL [1] with 4 main types recognized to date,

\footnotetext{
* Correspondence: sorkina@bk.ru

Endocrinology Research Centre, 11, ulitsa Dmitriya Ulianova, Moscow, Russian Federation 117036, Russia
}

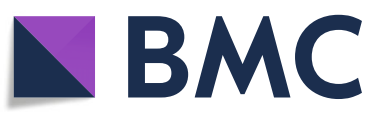

(c) The Author(s). 2020 Open Access This article is licensed under a Creative Commons Attribution 4.0 International License, which permits use, sharing, adaptation, distribution and reproduction in any medium or format, as long as you give appropriate credit to the original author(s) and the source, provide a link to the Creative Commons licence, and indicate if changes were made. The images or other third party material in this article are included in the article's Creative Commons licence, unless indicated otherwise in a credit line to the material. If material is not included in the article's Creative Commons licence and your intended use is not permitted by statutory regulation or exceeds the permitted use, you will need to obtain permission directly from the copyright holder. To view a copy of this licence, visit http://creativecommons.org/licenses/by/4.0/. The Creative Commons Public Domain Dedication waiver (http://creativecommons.org/publicdomain/zero/1.0/) applies to the data made available in this article, unless otherwise stated in a credit line to the data. mental retardation and metabolic disorders, with CGL type 1 and 2 being the most common ones [2]. The general prevalence of CGL is about 0.1: 100,000 of population, with certain exceptions: Brazilians (the state of Rio Grande do Norte, Brazil, has one of the highest CGL prevalence rates worldwide, up to 498:100,000) [3], Lebanese 0.5:100,000; Portuguese 0,2:100,000; Omanis 4: 100,000 [4]. Currently there are only 27 patients from 20 
families reported to have CGL type 4 . In this article we have reported an unusual clinical presentation of the first Russian patient with CGL type 4 .

\section{Case presentation}

A 36-year-old female patient of Tatarian origin was referred to the Endocrinology Research Centre, Moscow, with a diagnosis of type 1 diabetes mellitus complicated by diabetic foot syndrome. According to the medical documents, generalized lipoatrophy developed during the first months of life, and from the early childhood she suffered from an umbilical hernia, muscular hypotonia and delayed motor development (without mental retardation). Later moderate amyotrophy of the muscles of the
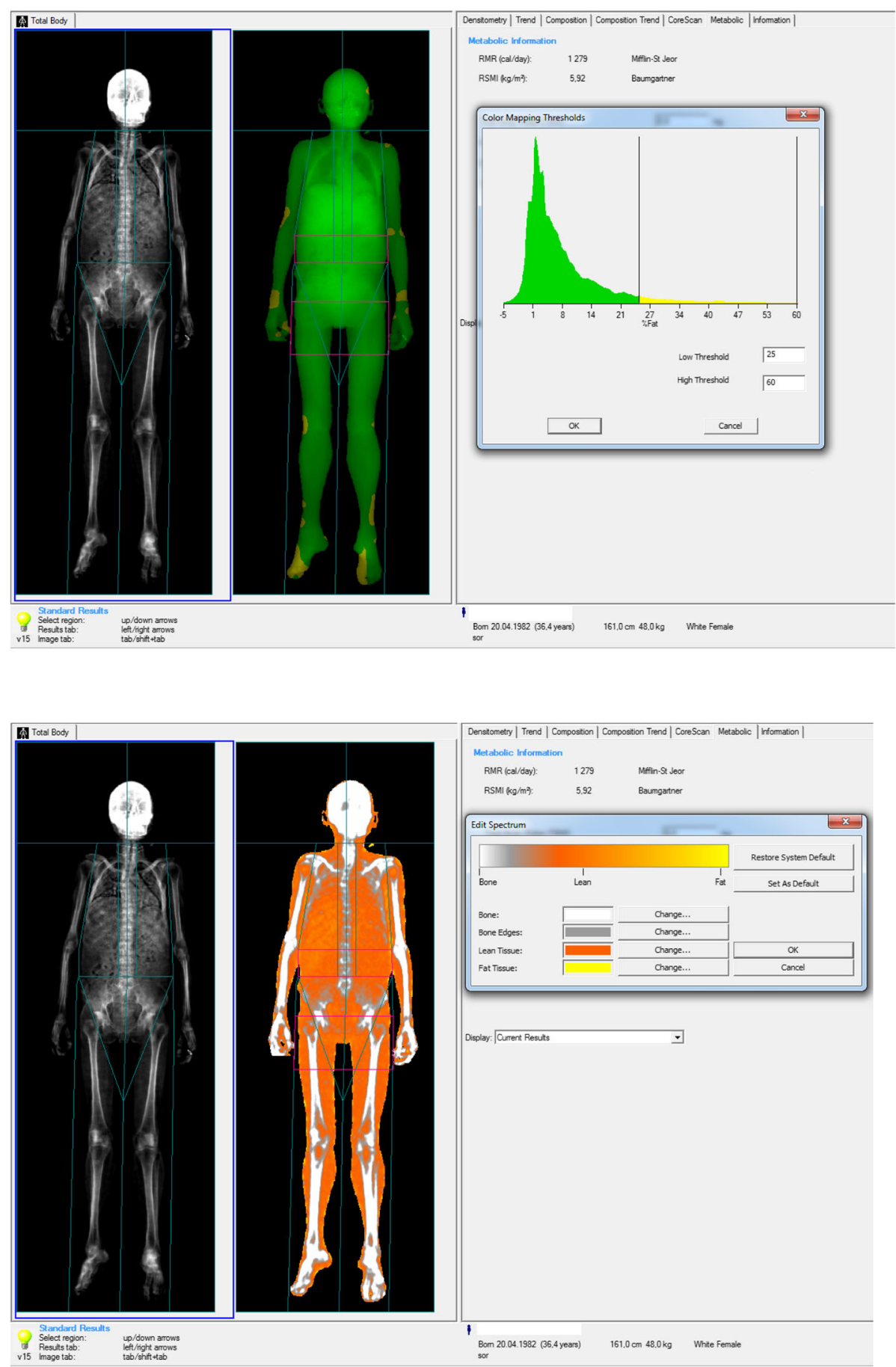

Fig. 1 "Total body" densitometry 
shoulder girdle developed, with a lack of reflexes in the legs, muscle weakness and myalgia of lower extremities. Between the ages of 17 and 20 the patient underwent multiple surgeries for dolichosigmoid, perforation of diverticula and peritonitis, which resulted in local muscular weakness and malabsorption leading to generalized muscular weakness and dysphagia. At 19 years of age diabetes mellitus type 1 was diagnosed with normal body weight but for 2 years the patient was well compensated by a diet with fast carbohydrates restriction. At the age of 21 , she started insulin therapy. A wound defect (trophic ulcer) in the area of the inner surface of the right thigh was diagnosed at the age of 35; after a few months, diabetic neuro-osteoarthropathy of the right foot was also diagnosed. For 3 months, the patient used a Total Contact Cast with positive effects. The patient had amenorrhea with 2 episodes of menorrhagia in her life between the ages of 18 and 19. Bilateral cataracts were first diagnosed at the age of 22, and were treated surgically 12 years later. Marked diffuse osteoporosis was diagnosed at the age of 28 by a multi-layer spiral CT (Computed Tomography) scan.

\section{Physical examination}

She had acromegaloid features, phlebomegaly and hypertrophy of the skeletal muscles in the upper and lower extremities, muscular hypotonia, generalized lipoatrophy, but no signs of hirsutism and clitoromegaly were found. Her height was $160 \mathrm{~cm}$, weight $46.8 \mathrm{~kg}$, BMI (Body mass index) $18.1 \mathrm{~kg} / \mathrm{m}^{2}$.

\section{Diagnostic tests}

Skin fold measurements, impedancemetry and "Total body" densitometry showed a significant decrease of subcutaneous fat tissue. The skin fold measurements were as following: supraclavicular skin fold, $4 \mathrm{~mm}$; subscapular skin fold, $6 \mathrm{~mm}$; triceps skin fold, $4 \mathrm{~mm}$; anterior surface of the abdomen skin fold, $4 \mathrm{~mm}$; hip skin fold, $6 \mathrm{~mm}$; anterior surface of the thigh skin fold, $6 \mathrm{~mm}$; posterior surface of the tibia skin fold, $3 \mathrm{~mm}$. Impedancemetry showed $11.9 \%$ of body fat, and "Total body" densitometry demonstrated $7.8 \%$ of total fat (Fig. 1). An abdominal ultrasound showed hepatosplenomegaly with severe hepatic steatosis. There was no cardiac pathology, except sinus tachycardia shown in the electrocardiogram. The densitometry showed severe osteoporosis of the lumbar spine (T-score L1-L4: - 5.6), osteoporosis of the proximal femur (T-score Neck: -5.4$)$. The laboratory data is presented in Table 1.

\section{Family history}

(Fig. 2): a consanguineous marriage of grandparents (cousins) from the father's side, type 2 diabetes (father and grandmother from the father's side), breast cancer (father's sister), acute myocardial infarction (2 father's brothers), arterial hypertension (2 father's brothers), bicornuate uterus and endometriosis (sister), Crohn's disease (cousin from the father's side), arterial hypertension and obesity (mother), death in early childhood from the unknown reason (mother's brother and sister). The patient reported that the grandmother from the father's side had a short stature.

The patient received insulin therapy (insulin glargine $20 \mathrm{U} /$ day, insulin glulisine $40 \mathrm{U} /$ day), nephroprotective therapy (enalapril $2.5 \mathrm{mg} /$ day), bisoprolol $5 \mathrm{mg} /$ day for tachycardia, antihyperuricemic therapy (allopurinol 150 $\mathrm{mg} /$ day), the native form of vitamin $\mathrm{D}$, alfacalcidol and calcium for osteoporosis. The patient also receives symptomatic therapy for gastrointestinal pathology and nutritional therapy.

Based on typical clinical signs of generalized lipodystrophy (total lipoatrophy, muscular hypertrophy, phlebomegaly, acromegaloid features, hypertriglyceridemia,

Table 1 Laboratory data (Blood. Age 36 years)

\begin{tabular}{|c|c|c|}
\hline Variables & Values & Normal range \\
\hline Fasting glucose, mmol/l & 8.8 & $3.1-6.1$ \\
\hline $\mathrm{HbA} 1 \mathrm{c}, \%$ & 7.3 & $4-6$ \\
\hline C-peptide, ng/ml & 0.928 & $1.1-4.4$ \\
\hline Anti-tyrosine phosphatase antibodies, $\mathrm{U} / \mathrm{ml}$ & 0.144 & neg. $<8$ \\
\hline Anti-islet cell antibodies, $\mathrm{U} / \mathrm{ml}$ & 0.58 & neg. $<0.95$ \\
\hline Anti-insulin antibodies, $\mathrm{U} / \mathrm{ml}$ & 17 & pos. $>10$ \\
\hline Zinc transporter 8 antibodies, $\mathrm{U} / \mathrm{ml}$ & 1.436 & neg. $<15$ \\
\hline Anti-GAD antibodies, $\mathrm{U} / \mathrm{ml}$ & 0.7 & neg. $<1$ \\
\hline Total cholesterol, mmol// & 5.55 & $3.3-5.2$ \\
\hline HDL cholestrol, mmol/l & 0.452 & $1.15-2.6$ \\
\hline LDL cholestrol, mmol/l & 1.435 & $1.1-3$ \\
\hline Triglycerides, mmol// & 8.14 & $0.1-1.7$ \\
\hline Leptin, ng/ml & 5.382 & $3.7-11.1$ \\
\hline Adiponectin, ng/ml & 2.54 & $8.2-19$ \\
\hline Creatinine kinase, U/I & 472 & $29-168$ \\
\hline$A L T, U / I$ & 42 & $0-55$ \\
\hline AST, U/I & 75 & $5-34$ \\
\hline GGT, U / I, & 139 & $9-36$ \\
\hline Calcium, mmol/l & 2.28 & $2.15-2.55$ \\
\hline Ionized calcium, mmol/l & 0.9 & $1.03-1.29$ \\
\hline Vitamin D, ng / ml & 27.2 & $>30$ \\
\hline Creatinine, $\mathrm{mcmol} / \mathrm{l}$ & 69.2 & $50-98$ \\
\hline CKD - EPI, $\mathrm{ml} / \mathrm{min} / 1,73 \mathrm{~m}^{2}$ & 98 & $90-120$ \\
\hline Urea, mmol/l & 9.4 & $2.5-6.7$ \\
\hline Uric acid, $\mu \mathrm{mol}$ & 444.25 & $142-339$ \\
\hline
\end{tabular}

HbA1c Hemoglobin A1c, GAD Glutamic acid decarboxylase, HDL High-density lipoprotein, LDL Low-density lipoprotein, ALT Alanine aminotransferase, AST Aspartate aminotransferase, GGT Gamma-glutamyl transpeptidase, CKD - EPI Chronic Kidney Disease Epidemiology Collaboration 


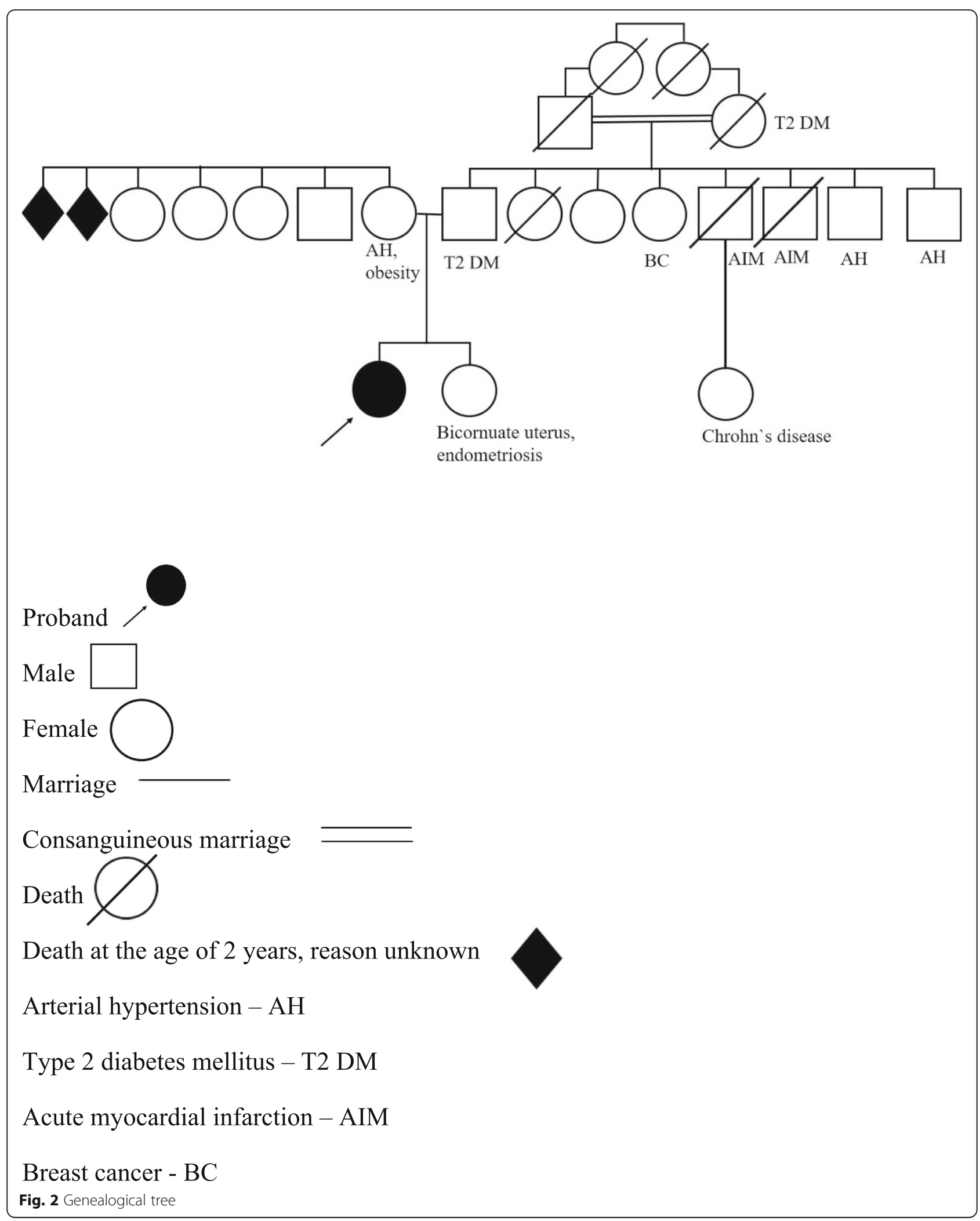




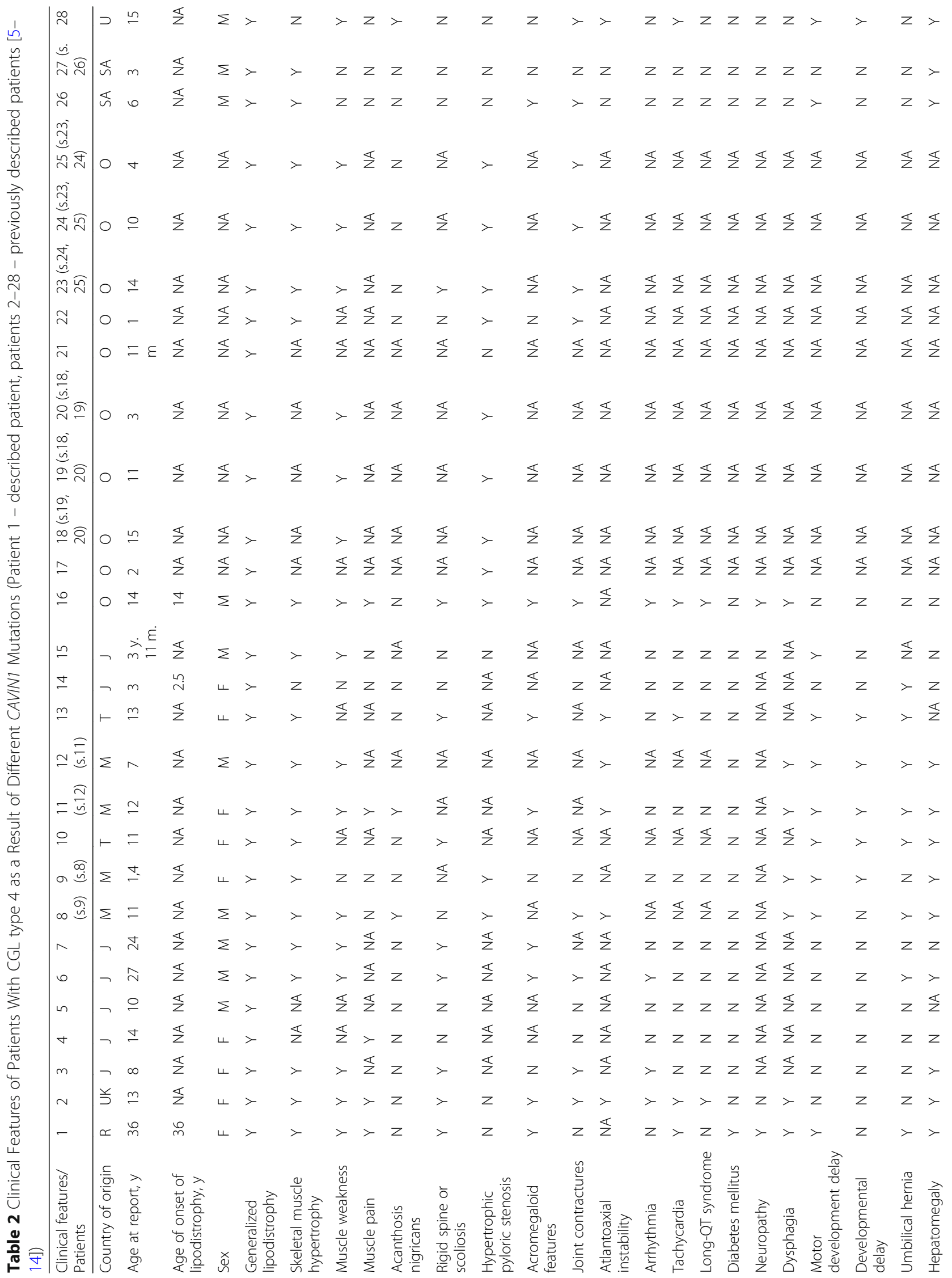




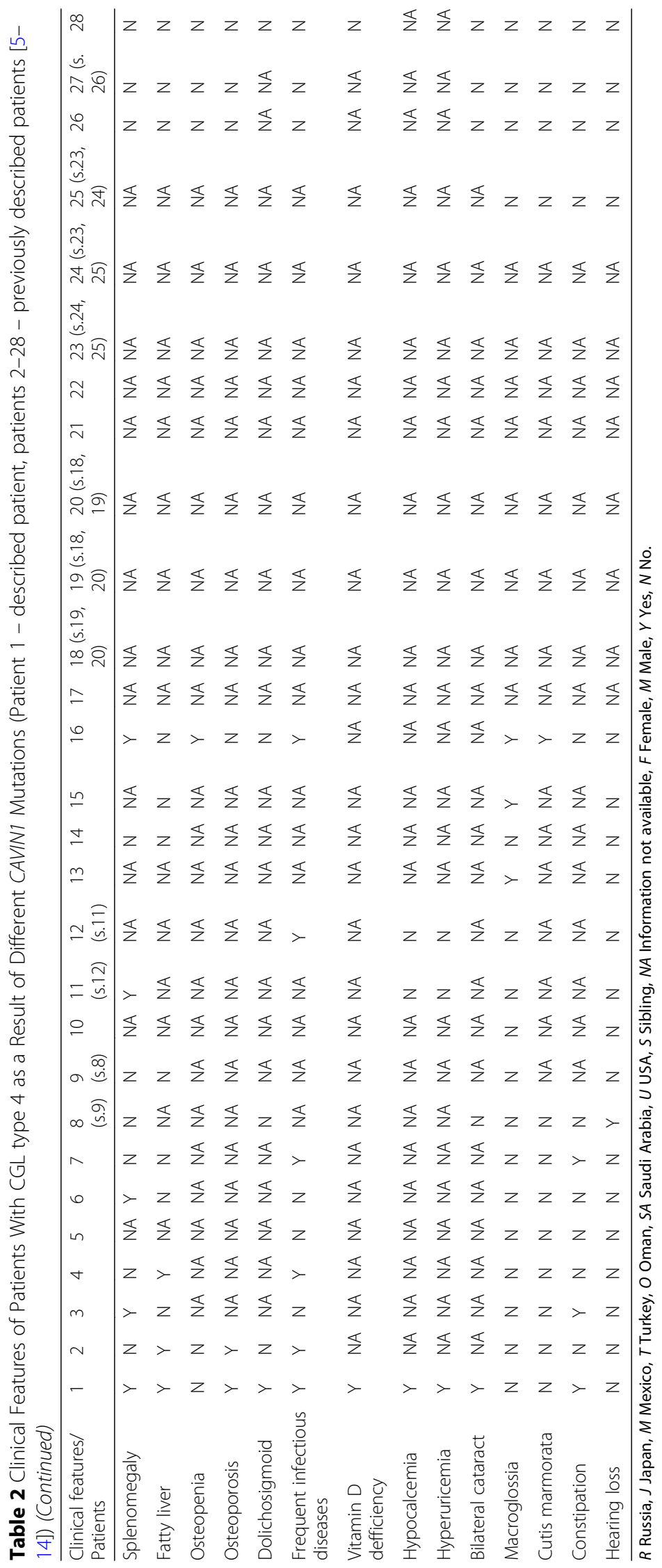




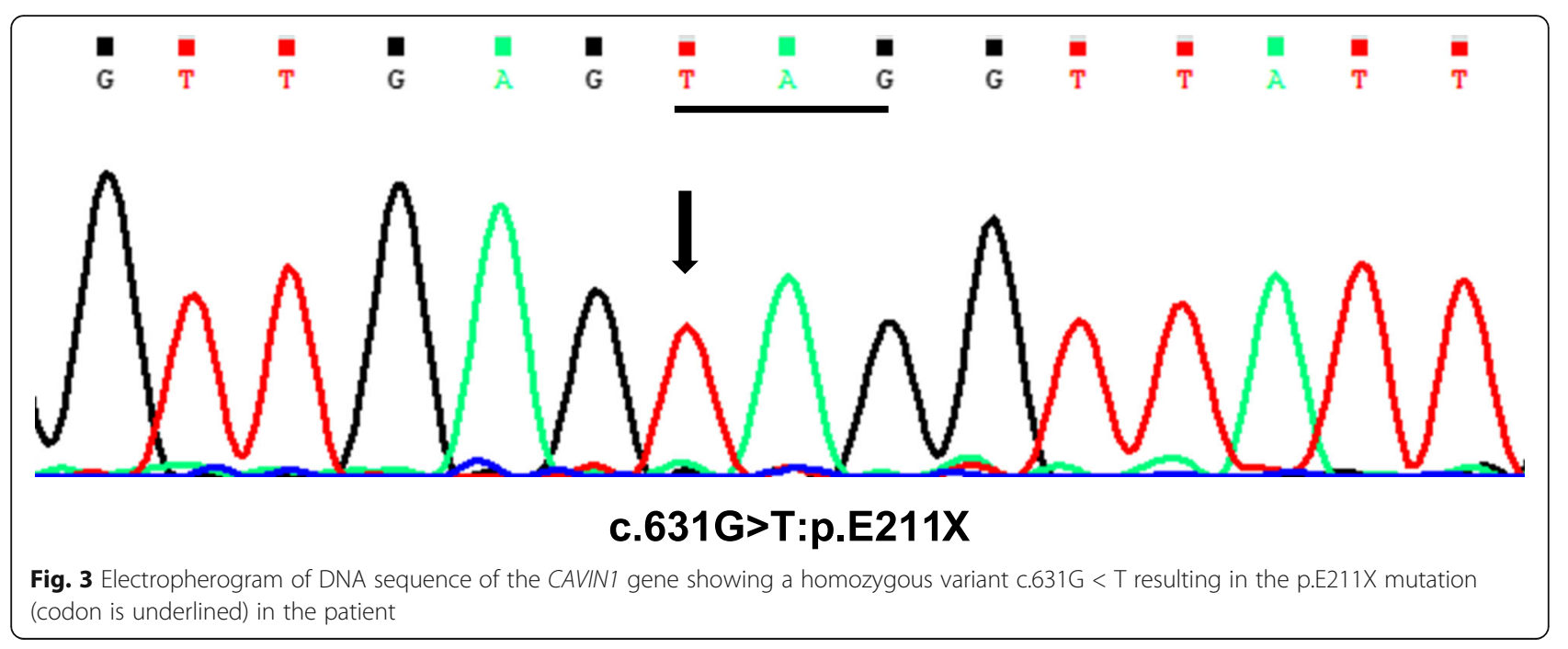

hepatosplenomegaly, steatohepatitis) and early onset of the disease, CGL was suspected. Taking into account muscular pathology, CGL type 4 appeared probable. Due to the variety of clinical features of different types of lipodystrophy syndromes and progeroid syndromes sequencing of 18 lipodystrophy candidate genes (AGPAT2, BSCL2, CAV1, CAVIN1, PSMB8, LMNA, PPARG, PLIN1, AKT2, CIDEC, LIPE, LMNB2, PIK3CA, PPP1R3A, POLD1, WRN, ZMPSTE24, BANF1) using a custom Ion Ampliseq panel and Personal Genome Machine (ThermoFisher Scientific, Waltham, MA, USA) semiconductor sequencer (Ion Torrent) was performed. A novel pathogenic homozygous variant c.631G < T: p.E211X was detected in the CAVIN1 gene (Fig. 3), confirming the diagnosis of CGL type 4.

\section{Discussion}

All types of CGL are characterized by a near-complete lack of fat starting at birth or infancy, prominent muscles, phlebomegaly, hepatomegaly, umbilical prominence and a voracious appetite in childhood. Genetic and phenotypic heterogeneity is well documented in patients with CGL, as well as the overlap of clinical findings in different types of CGL.

CGL type 4 is a unique form of generalized lipodystrophy characterized by all the symptoms listed above as well as myopathy, cardiac arrhythmias, skeletal abnormalities and gastrointestinal dysmotility (Tables 2 and 3). CGL type 4 is usually associated with metabolic abnormalities secondary to insulin resistance, however acanthosis nigricans has been reported in only 2 patients out of 27 described patients with CGL type 4.

Our patient had all the described signs except acanthosis nigricans. However, other metabolic and clinical manifestations, which were not found in other patients with this form of CGL, are noteworthy: diabetes mellitus, vitamin D
Table 3 Mutations in CAVIN1 gene [5-14]

\begin{tabular}{|c|c|}
\hline Patients & Mutations \\
\hline Patient 1 & c.631G > T:p.E211X(homozygous) \\
\hline Patient 2 & c.362dupT(homozygous) \\
\hline Patient 3 & c.696-697insC(homozygous) \\
\hline Patient 4 & c.696-697insC(homozygous) \\
\hline Patient 5 & c.696-697insC(homozygous) \\
\hline Patient 6 & c.696-697insC(homozygous) \\
\hline Patient 7 & c.696-697insC/c.525delG \\
\hline Patient 8 & c.135delG \\
\hline Patient 9 & c.135delG \\
\hline Patient 10 & c.481-482insGTGA \\
\hline Patient 11 & c.518-521delAAGA \\
\hline Patient 12 & c.518-521delAAGA \\
\hline Patient 13 & c. $259 C>T$ \\
\hline Patient 14 & c.512CNA /c.696_697insC \\
\hline Patient 15 & c.696_697insC \\
\hline Patient 16 & c.160delG (homozygous) \\
\hline Patient 17 & c.160delG (homozygous) \\
\hline Patient 18 & c.160delG (homozygous) \\
\hline Patient 19 & c.160delG (homozygous) \\
\hline Patient 20 & c.160delG (homozygous) \\
\hline Patient 21 & c.160delG (homozygous) c.45G > A (homozygous) \\
\hline Patient 22 & c.160delG (homozygous) \\
\hline Patient 23 & c.160delG (homozygous) \\
\hline Patient 24 & c.160delG (homozygous) \\
\hline Patient 25 & c.160delG (homozygous) \\
\hline Patient 26 & C.550G > T \\
\hline Patient 27 & c.550G $>\mathrm{T}$ \\
\hline Patient 28 & c.518521 delAAGA and c.471 + 1G.T \\
\hline
\end{tabular}


deficiency, hypocalcemia, hyperuricemia, bilateral cataracts. Dolichosigmoid was not found in other patients with CGL type 4, but can be attributed to the disorders of gastrointestinal tract connected with this form of CGL, like hypertrophic pyloric stenosis and constipation.

The remaining endogenous insulin secretion (C-peptide level $0.9 \mathrm{ng} / \mathrm{ml}$ ) is not typical for type 1 diabetes over an 18-year period. Furthermore, for 2 years the patient was on a diet, without insulin therapy, with no history of ketoacidosis. Anti-insulin antibodies are positive $(17 \mathrm{U} / \mathrm{ml})$, which can be a result of a long-term insulin therapy, the rest of the immunological markers for type 1 diabetes are negative (Table 1 ). Thus, it is more likely that the patient has lipoatrophic diabetes rather than type 1 diabetes, despite the lack of evidence of insulin resistance (no acanthosis nigricans, insulin $60 \mathrm{U} /$ day, insulin resistance indexes assessment was compromised due to a long-term experience of diabetes mellitus, and a wound defect of the right thigh). Nevertheless, insulin therapy is a front-line therapy for this patient because of the concomitant diseases.

Vitamin D deficiency and hypocalcemia, found in our patient, was previously found only in CGL type 3 . However, osteoporosis was reported in CGL types 3 and 4 and is typical for progeroid syndromes which are also associated with generalized lipodystrophy.

Bilateral cataracts were not previously described in any CGL forms, but they are a typical sign of Werner syndrome ("progeria of adults") [15].

Hyperuricemia has not been reported in CGL, however it was found in familial partial lipodystrophy type 3 caused by PPARG mutation [16] In addition, it is a frequent component of metabolic syndrome.

In generalized lipodystrophy, metreleptin (with diet) is a first-line treatment for metabolic and endocrine abnormalities and may be considered as a prevention of these comorbidities in children [1].

\section{Conclusions}

In comparison with previously reported patients with CGL type 4, our patient has insulin dependent diabetes mellitus, vitamin D deficiency, hypocalcemia, bilateral cataracts, hyperuricemia. All these manifestations are known to be associated with other lipodystrophy syndromes, but to our knowledge it is the first time they have been shown to be associated with CGL type 4 .

\section{Abbreviations}

BMI: Body mass index; CGL: Congenital generalized lipodystrophy;

CT: Computed Tomography

\section{Authors' contributions}

ES is the main author, to whom belongs the idea of writing the article, clinically diagnosed congenital generalized lipodystrophy in the patient and made a major contribution to the writing of the manuscript. PM prepared tables, Fig. 2, took part in writing the manuscript. LB and IU were the attending physicians of the patient, suspected lipoatrophic diabetes in the patient, provided and interpreted the data of the examination, laboratory and clinical studies, reviewed the manuscript. TC performed and interpreted the patient's "Total body" densitometry, prepared Fig. 1, reviewed the manuscript. AT performed and interpreted the genetic study of the patient, reviewed the manuscript and made substantial suggestions. The authors read and approved the final manuscript.

\section{Funding}

The study was supported by the grant of Russian Science Foundation №1775-30035.

\section{Availability of data and materials}

Not applicable.

Ethics approval and consent to participate

A written informed consent for genetic studies was obtained from the patient, and the protocol of the study was approved by the Local ethical committee of the Endocrinology Research Centre.

\section{Consent for publication}

Written informed consent for publication of her clinical details and clinical images was obtained from the patient.

\section{Competing interests}

All authors declare that there is no conflict of interest that could be perceived as prejudicing the impartiality of the research reported.

Received: 8 January 2020 Accepted: 3 May 2020

Published online: 14 May 2020

References

1. Brown RJ, Araujo-Vilar D, Cheung PT, Dunger D, Garg A, Jack M, et al. The diagnosis and Management of Lipodystrophy Syndromes: a multi-society practice guideline. J Clin Endocrinol Metab. 2016;101(12):4500-11.

2. Hussain I, Garg A. Lipodystrophy syndromes. Endocrinol Metab Clin North Am. 2016:45(4):783-97.

3. de Azevedo Medeiros LB, Cândido Dantas VK, Craveiro Sarmento AS, AgnezLima LF, Meireles AL, Xavier Nobre TT, et al. High prevalence of BerardinelliSeip congenital lipodystrophy in Rio Grande do Norte state, Northeast Brazil. Diabetol Metab Syndr. 2017;9(1):80 1-6.

4. Van Maldergem L. Berardinelli-Seip congenital lipodystrophy. In: Adam MP, Ardinger HH, Pagon RA, Wallace SE, LJH B, Stephens K, Amemiya A, editors. GeneReviews ${ }^{\circledast}$. Seattle: University of Washington, Seattle; 2003. p. 1-17. http://www.ncbi.nlm.nih.gov/books/NBK1212/ Accessed 29 Dec 2019.

5. Rajab A, Straub V, McCann LJ, Seelow D, Varon R, Barresi R, et al. Fatal cardiac arrhythmia and long-QT syndrome in a new form of congenital generalized lipodystrophy with muscle rippling (CGL4) due to PTRF-CAVIN mutations. PLoS Genet. 2010;6(3):e1000874 1-10.

6. Hayashi YK, Matsuda C, Ogawa M, Goto K, Tominaga K, Mitsuhashi S, et al. Human PTRF mutations cause secondary deficiency of caveolins resulting in muscular dystrophy with generalized lipodystrophy. J Clin Invest. 2009;119: 2623-33.

7. Shastry S, Delgado MR, Dirik E, Turkmen M, Agarwal AK, Garg A. Congenital generalized lipodystrophy, type 4 (CGL4) associated with myopathy due to novel PTRF mutations. Am J Med Genet A. 2010;152A:2245-53.

8. Simha V, Agarwal AK, Aronin PA, lannaccone ST, Garg A. Novel subtype of congenital generalized lipodystrophy associated with muscular weakness and cervical spine instability. Am J Med Genet A. 2008;146A:2318-26.

9. Akinci G, Topaloglu H, Akinci B, Onay H, Karadeniz C, Ergul Y, et al. Spectrum of clinical manifestations in two young Turkish patients with congenital generalized lipodystrophy type 4. Eur J Med Genet. 2016;59(6-7): 320-4.

10. Dwianingsih EK, Takeshima Y, Itoh K, Yamauchi Y, Awano H, Malueka RG, et al. A Japanese child with asymptomatic elevation of serum creatine 
kinase shows PTRF-CAVIN mutation matching with congenital generalized lipodystrophy type 4. Mol Genet Metab. 2010;101(2-3):233-7.

11. Murakami N, Hayashi YK, Oto Y, Shiraishi M, Itabashi H, Kudo K, et al. Congenital generalized lipodystrophy type 4 with muscular dystrophy: clinical and pathological manifestations in early childhood. Neuromuscul Disord. 2013;23(5):441-4.

12. Takeyari S, Takakuwa S, Miyata K, Yamamoto K, Nakayama H, Ohata Y, et al. Metreleptin treatment for congenital generalized lipodystrophy type 4 (CGL4): a case report. Clin Pediatr Endocrinol. 2019;28(1):1-7.

13. Jelani M, Ahmed S, Almramhi MM, Mohamoud HS, Bakur K, Anshasi W, et al. Novel nonsense mutation in the PTRF gene underlies congenital generalized lipodystrophy in a consanguineous Saudi family. Eur J Med Genet. 2015;58(4):216-21.

14. Patni N, Vuitch F, Garg A. Postmortem findings in a young man with congenital generalized lipodystrophy, type 4 due to CAVIN1 mutations. J Clin Endocrinol Metabolis. 2018;104(3):957-60.

15. Berger JR, Oral EA, Taylor SI. Familial lipodystrophy associated with neurodegeneration and congenital cataracts. Neurology. 2002;58(1):43-7.

16. Sorkina EL, Kalashnikova MF, Likhodey NV, Koksharova EO, Ustyuzhanin DV Mayorov AY, et al. Development of metabolic syndrome at a young age as a manifestation of familial partial lipodystrophy type 3 (PPARG mutation): the first description of its clinical case in Russia. Diabetes Mellitus. 2015; 18(3):99-105.

\section{Publisher's Note}

Springer Nature remains neutral with regard to jurisdictional claims in published maps and institutional affiliations.

Ready to submit your research? Choose BMC and benefit from:

- fast, convenient online submission

- thorough peer review by experienced researchers in your field

- rapid publication on acceptance

- support for research data, including large and complex data types

- gold Open Access which fosters wider collaboration and increased citations

- maximum visibility for your research: over $100 \mathrm{M}$ website views per year

At $\mathrm{BMC}$, research is always in progress.

Learn more biomedcentral.com/submissions 